AperTO - Archivio Istituzionale Open Access dell'Università di Torino

\title{
Structural deformation mechanisms of zeolites under pressure
}

\section{This is the author's manuscript}

Original Citation:

Availability:

This version is available http://hdl.handle.net/2318/80822

since

Terms of use:

Open Access

Anyone can freely access the full text of works made available as "Open Access". Works made available under a Creative Commons license can be used according to the terms and conditions of said license. Use of all other works requires consent of the right holder (author or publisher) if not exempted from copyright protection by the applicable law. 


\title{
Structural deformation mechanisms of zeolites under pressure
}

\section{Rossella Arletti, ${ }^{1}$ Orazio Ferro,,${ }^{1,} \uparrow$ Simona Quartieri, ${ }^{2}$ Alessandra Sani, ${ }^{3}$ GLORIA TABACCHI, ${ }^{4}$ AND GIOVANNA VEZZALinI ${ }^{1, *}$}

\author{
${ }^{1}$ Dipartimento di Scienze della Terra, Largo S. Eufemia, 19, I-41100 Modena, Italy \\ ${ }^{2}$ Dipartimento di Scienze della Terra, Salita Sperone 31, I-98166 Messina, S. Agata, Italy \\ ${ }^{3}$ European Synchrotron Radiation Facility, BP 220, F-38042 Grenoble Cedex, France \\ ${ }^{4}$ Dipartimento di Scienze Chimiche, Fisiche e Matematiche, Università dell'Insubria, via Lucini 3, I-22100, Como, Italy
}

\begin{abstract}
The $\mathrm{H} P$ behavior of the natural zeolite yugawaralite and of the synthetic zeolite Na-A was studied by in situ synchrotron $\mathrm{X}$-ray powder diffraction, using a non-penetrating $P$-transmitting medium. The unit-cell parameters of yugawaralite were refined up to the pressure of $10 \mathrm{GPa}$, at which reductions were found of about 7, 2.4, 7, 1.3, and $15 \%$ for $a, b, c, \beta$, and $V$, respectively. Contractions of 6.5 and $18.4 \%$ were found for $a$ and $V$, respectively, for zeolite Na-A in the range $10^{-4}$ to $6.8 \mathrm{GPa}$. Diffraction patterns collected during decompression show that the effects induced by high pressure on both samples are almost completely reversible. These results are compared with those obtained under similar experimental conditions for other natural zeolites, with the aim of rationalizing the deformation mechanisms of these porous materials and comparing their flexibility under high-pressure and high-temperature conditions.
\end{abstract}

\section{INTRODUCTION}

Zeolites are both porous naturally occurring alumino-silicate minerals and important synthetic materials. Their industrial applications, as catalysts, selective absorbers, and ionic exchangers, are based on their unique physicochemical properties, which have made zeolites one of the most interesting classes of natural and synthetic materials since their original description. Zeolites may also play an important role in the fabrication of nanometer-sized dots, wires, and surfaces embedded in the nano-cavities of a solid ordered matrix (e.g., Alivisatos 1996).

The efficient application of zeolites in chemical processes for industrial purposes requires an in-depth understanding of the behavior of the framework under the operative conditions, which may be different from the ambient ones. To this end the thermal stability and the dehydration mechanisms of zeolites have been intensively studied for many years (i.e., Bish and Carey 2001), whereas only recently has attention been devoted to the study of their pressure-induced modifications. Most previous work has been on: (1) the dependence of zeolite compressibility upon the molecular size of the pressure-transmitting media, which are defined as penetrating or non-penetrating (Hazen 1983; Hazen and Finger 1984; Kholdeev et al. 1987; Bazhan et al. 1999); (2) pressure-induced amorphization and the reversibility of this process upon decompression (Gillet et al. 1996; Goryainov et al. 1996; Huang 1998; Huang and Havenga 2001; Liu et al. 2001; Rutter et al. 2001); and (3) the effect of pressure on ionic conductivity and molecular self-diffusion (Belitsky et al. 1987; Secco and Huang 1999; Rutter et al. 2000; Moroz et al. 2001). In general, little structural information is available and a thorough understanding of pressure-

*E-mail: giovanna@unimo.it

$\dagger$ Deceased February 28, 2003 induced deformation mechanisms has not yet been achieved. Moreover, only a few studies have investigated possible pressure-induced polymorphic phase changes, in particular with non-penetrating pressure-transmitting media (fibrous zeolites: Belitsky et al. 1992; Goryainov and Smirnov 2001; Lee et al. 2002; Ballone et al. 2002; Comodi et al. 2002; analcime and wairakite: Hazen and Finger 1979; Velde and Besson 1981; Goryainov et al. 1999; heulandite: Comodi et al. 2001; Vezzalini et al. 2001; synthetic zeolite RHO: Lee et al. 2001; bikitaite: Ferro et al. 2002; Comodi et al. 2003).

Here we present new data on the compressibility and deformational reversibility of yugawaralite (hereafter YUGA) and synthetic zeolite Na-A (ZEOA), obtained by in situ synchrotron X-ray powder diffraction (XRPD) experiments. A further purpose of this paper is to compare the high-pressure behavior of the zeolites studied using both single-crystal and X-ray powder diffraction methods. Moreover, since the stability and structural response of zeolites under moderately high pressure is, in general, different to that observed in high-temperature studies, we will compare the deformation mechanisms of these porous materials under the different physical conditions. The zeolites compared here are characterized by different framework topologies and extra-framework cations and cover a wide range of framework densities. Moreover, they have different framework flexibilities, as verified by their different behavior after dehydration and cation exchange. Obviously, owing to the lack of comparable high-pressure structural data in the literature, this discussion does not claim to interpret structural behaviors in an exhaustive way since these are certainly dependent on numerous and complex factors.

\section{EXPERIMENTAL METHODS}

The YUGA sample used in this work is from Yugawara (Japan) $\left[\mathrm{Ca}_{1.96} \mathrm{Na}_{0.01} \mathrm{~K}_{0.01}\left(\mathrm{Al}_{3.95} \mathrm{Si}_{12.06}\right) \mathrm{O}_{32} \cdot 9.01 \mathrm{H}_{2} \mathrm{O}\right]$ and synthetic ZEOA, in the sodium form, is a commercial BDH Chemicals 
sample $\left[\mathrm{Na}_{12}\left(\mathrm{Al}_{12} \mathrm{Si}_{12} \mathrm{O}_{48}\right) \cdot 27 \mathrm{H}_{2} \mathrm{O}\right]$.

The XRPD experiments were performed using the ID09 beamline at ESRF (European Synchrotron Radiation Facility, Grenoble), at a fixed wavelength of $0.41782 \AA$, using a diamond anvil cell and silicon oil as non-penetrating pressuretransmitting medium (Gillet et al. 1996). The choice of non-penetrating pressure-transmitting medium used in the highpressure studies of porous materials is always a compromise between the molecule dimensions, which must be larger than those of the pores, and the degree of hydrostaticity. It is well known that these media can suffer from a lack of hydrostaticity at high pressure. The hydrostaticity of silicon oil can be considered satisfactory at least up to about $5 \mathrm{GPa}$, on the basis of the close agreement between the results obtained from single crystals of heulandite and bikitaite using glycerol (Comodi et al. 2001, 2003) and silicon oil on powders (Vezzalini et al. 2001; Ferro et al. 2002). Moreover, Le Bihan et al. (1996) studied several intermetallic uranium compounds under high pressure with different pressure-transmitting media (silicon oil, ethanol-methanol-water, and liquid argon) and observed a stress due to the solidification of silicon oil at about $9 \mathrm{GPa}$. However, at lower pressure no significant difference was observed with respect to the other pressure transmitting media. Above $5 \mathrm{GPa}$ we cannot, however, rule out a contribution of deviatoric stress to the peak broadening of our powder diffraction spectra.

The pressures were measured by the ruby fluorescence method (Forman et al. 1972) on the non-linear hydrostatic pressure scale (Mao et al. 1986). The estimated error in the pressure values is $0.1 \mathrm{GPa}$. The experiments were performed from $10^{-4}$ up to 11 and $6.8 \mathrm{GPa}$, for YUGA and ZEOA, respectively, with pressure increments of $0.5-1 \mathrm{GPa}$. Some other patterns were collected during decompression. A MAR345 detector (pixel dimension $100 \mu \mathrm{m}$ ) was used at a fixed distance of 446.72 $\mathrm{mm}$ from the samples; the exposure time was $34 \mathrm{~s}$ for each pressure. The samples were rocked by $\pm 3^{\circ}$ in $\omega$ to reduce texture in the diffraction images. One-dimensional diffraction patterns were obtained in the range $0-22^{\circ} 2 \theta$ (YUGA) by integrating the two dimensional images with the program FIT2D (Hammersley et al. 1996) and are reported in Figures 1 and 2 for YUGA and ZEOA, respectively.

The unit-cell refinements were carried out in the $2 \theta$ range 2$20^{\circ}$ up to 10 and $6.8 \mathrm{GPa}$ for YUGA and ZEOA, respectively, by means of the GSAS program (Larson and Von Dreele 1994) using the Rietveld method for YUGA and the Le Bail method for ZEOA. The atomic coordinates of the structural models are from Kvick et al. (1986) and Gramlich and Meier (1971) for YUGA and ZEOA, respectively. The background curves were fitted by a Chebyshev polynomial with 22 and 20 coefficients for YUGA and ZEOA, respectively. The pseudo-Voight profile function proposed by Thomson et al. (1987) was used with refined Gaussian (GW) and Lorentzian (LX) terms for YUGA, while for ZEOA LY was also refined above 3.1 GPa. An asymmetry correction from Finger et al. (1994) was used for YUGA. The refined cell parameters as a function of pressure are reported in Tables 1 and 2, and in Figures 3 and 4, for YUGA and ZEOA, respectively. The isothermal bulk modulus of all the zeolites studied here were determined with the EOS-FIT program (Angel 2001) using a second- or third-order Birch-Murnaghan equation of state (Birch 1952).
TABLE 1. Experimental unit-cell parameters of yugawaralite at different pressures

\begin{tabular}{lllccc}
\hline \hline$P(\mathrm{GPa})$ & \multicolumn{1}{c}{$a(\AA)$} & \multicolumn{1}{c}{$b(\AA)$} & $c(\AA)$ & $\beta\left(^{\circ}\right)$ & $V\left(\AA^{\circ}\right)$ \\
\hline $10^{-4}$ & $6.7239(5)$ & $13.9952(7)$ & $10.0482(8)$ & $111.182(4)$ & $881.7(1)$ \\
0.2 & $6.7060(6)$ & $13.9809(9)$ & $10.0262(9)$ & $111.160(5)$ & $876.6(1)$ \\
0.5 & $6.6813(7)$ & $13.964(1)$ & $9.987(1)$ & $111.058(5)$ & $869.6(1)$ \\
1.0 & $6.6515(6)$ & $13.943(1)$ & $9.9418(9)$ & $110.974(5)$ & $860.9(1)$ \\
1.5 & $6.6195(7)$ & $13.917(1)$ & $9.891(1)$ & $110.882(5)$ & $851.4(1)$ \\
2.0 & $6.561(1)$ & $13.927(2)$ & $9.759(2)$ & $110.57(1)$ & $835.0(3)$ \\
2.4 & $6.531(1)$ & $13.926(2)$ & $9.706(2)$ & $110.46(1)$ & $827.0(3)$ \\
3.1 & $6.503(2)$ & $13.909(2)$ & $9.648(2)$ & $110.39(1)$ & $818.0(3)$ \\
3.9 & $6.463(2)$ & $13.873(3)$ & $9.581(3)$ & $110.32(2)$ & $805.5(4)$ \\
5.3 & $6.390(2)$ & $13.829(4)$ & $9.489(3)$ & $110.22(2)$ & $786.8(5)$ \\
6.3 & $6.355(3)$ & $13.802(5)$ & $9.451(4)$ & $110.17(3)$ & $778.1(6)$ \\
7.6 & $6.310(3)$ & $13.759(5)$ & $9.402(5)$ & $110.09(3)$ & $766.7(6)$ \\
8.8 & $6.264(4)$ & $13.708(7)$ & $9.364(6)$ & $109.94(4)$ & $755.9(8)$ \\
10 & $6.224(5)$ & $13.655(8)$ & $9.326(7)$ & $109.73(5)$ & $746.1(9)$ \\
4.3 rev & $6.363(5)$ & $13.856(8)$ & $9.604(7)$ & $110.10(9)$ & $795.1(1)$ \\
0.9 rev & $6.653(1)$ & $14.040(2)$ & $9.968(2)$ & $110.96(1)$ & $869.41(3)$ \\
0.8 rev & $6.6817(9)$ & $14.019(1)$ & $10.024(1)$ & $111.165(8)$ & $875.63(2)$ \\
\hline
\end{tabular}

TABLE 2. Experimental unit-cell parameters of zeolite Na-A at different pressures

\begin{tabular}{llr}
\hline \hline$P(\mathrm{GPa})$ & $a(\AA)$ & \multicolumn{1}{c}{$V\left(\AA^{\circ}\right)$} \\
\hline $10^{-4}$ & $24.590(2)$ & $14869(4)$ \\
0.3 & $24.49(1)$ & $14690(20)$ \\
0.4 & $24.45(1)$ & $14614(10)$ \\
0.7 & $24.35(1)$ & $14430(20)$ \\
1.3 & $24.14(1)$ & $14077(21)$ \\
1.8 & $23.98(1)$ & $13800(21)$ \\
2.2 & $23.87(1)$ & $13610(21)$ \\
2.8 & $23.76(1)$ & $13410(22)$ \\
3.1 & $23.66(2)$ & $13240(30)$ \\
3.6 & $23.56(2)$ & $13070(30)$ \\
4.1 & $23.44(3)$ & $12880(50)$ \\
4.7 & $23.32(3)$ & $12690(50)$ \\
5.3 & $23.21(3)$ & $12510(50)$ \\
6.8 & $22.98(5)$ & $12140(70)$ \\
4.4 & $23.16(4)$ & $12420(70)$ \\
3.0 & $23.41(4)$ & $12820(60)$ \\
0.0 & $24.59(2)$ & $14864(40)$ \\
\hline
\end{tabular}

\section{RESULTS}

Figures 1 and 2 show powder patterns for YUGA and ZEOA, respectively, as a function of pressure. For both samples, the peak intensities decrease and the peak profiles become broader with increasing pressure. These effects can be due to a number of factors: an increase in the long-range structural disorder, a reduction of the average crystallite size, or the presence of microstrain caused by deviatoric stress in the quasi-hydrostatic pressure-transmitting medium silicon oil (Yamanaka et al. 1997; Weidner et al. 1998; Fei and Wang 2000; Lee et al. 2002). Moreover, we did not observe the appearance of peaks not due to the YUGA and ZEOA space groups, thus ruling out any pressureinduced change of the original symmetry.

The images of all the X-ray powder diffraction spectra collected on the MAR345 image plate detector are characterized by the presence of numerous spots caused by the poor statistics of the diffraction data, resulting from the low mosaicity of the crystallites and the small volume hit by the beam. These factors, together with the low peak-to-background ratio, make it impossible to refine the crystal structure of the zeolites. Hence, only the unit-cell parameters were extracted from the powder patterns.

\section{Yugawaralite}

Yugawaralite is a Ca-zeolite $\left(\mathrm{CaAl}_{2} \mathrm{Si}_{6} \mathrm{O}_{16} \cdot 4 \mathrm{H}_{2} \mathrm{O}, \mathrm{Z}=2\right)$; its framework topology can be described by a pair of a five-mem- 


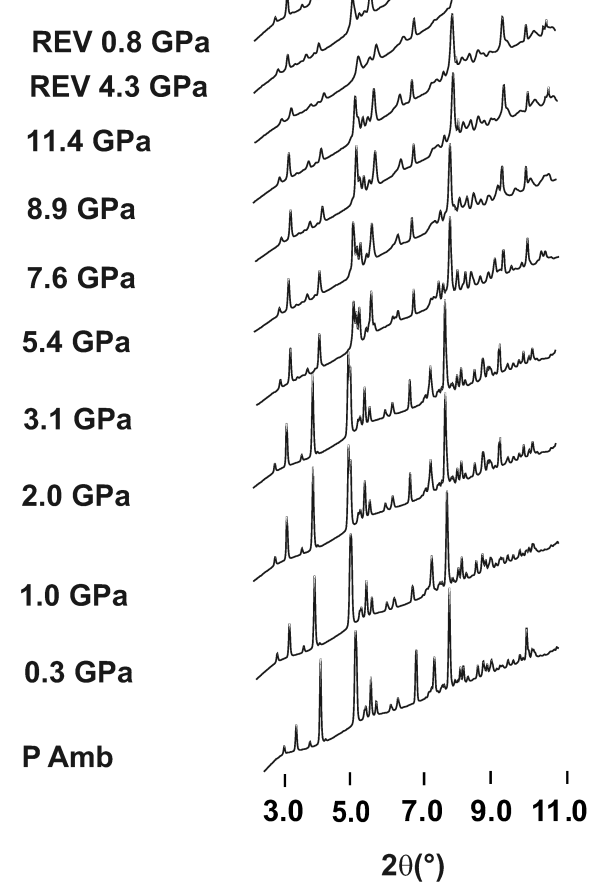

FIGURE 1. Selected integrated powder patterns of yugawaralite as a function of pressure. The two powder patterns at the top of the figure were collected during decompression.

bered rings sharing an edge. These units share one branch, thus forming chains running parallel to $\mathbf{a}$; each chain is connected to the adjacent one forming sheets in the ac plane. The sheets are superposed to form channels parallel to [100] and [001] limited by eight-rings (Fig. 5). The topological symmetry $C 2 /$ $m$ is reduced to the real symmetry $P c$ by $(\mathrm{Si}, \mathrm{Al})$ ordering; the unit-cell parameters become $a=6.700(1), b=13.972(2), c=$ 10.039(5) $\AA, \beta=111.07(2)^{\circ}$ (Kvick et al. 1986).

Figure 1 shows that the YUGA structure is very stable up to the highest investigated pressures and that no $\mathrm{X}$-ray amorphization is observed up to $11 \mathrm{GPa}$. Moreover, the features of the ambient pressure pattern are almost completely recovered upon decompression.

Table 1 and Figure 3a show the refined cell parameters as a function of pressure. The largest contraction in the range $0-10$ $\mathrm{GPa}$ is observed for cell volume (15\%); $a$ and $c$ contract by about $7 \%$, while very minor variations affect the $b(2.4 \%)$ and $\beta(1.3 \%)$ parameters. All cell parameters show two discontinuites between 1.5 and $2 \mathrm{GPa}$ (Fig. 3b) and between 3.9 and $5.3 \mathrm{GPa}$ (Fig. 3a). The corresponding decrease in the compressibilities (Table 3 ) suggests a change in the compression mechanism. The isothermal bulk modulus determined up to $4 \mathrm{GPa}$ using a second-order Birch-Murnaghan equation of state gives $K_{0}$ = 34(1) GPa. The empty circles in Figure 3a represent the cell volumes derived from three patterns collected during decompression. Their close agreement with the original values indicates that

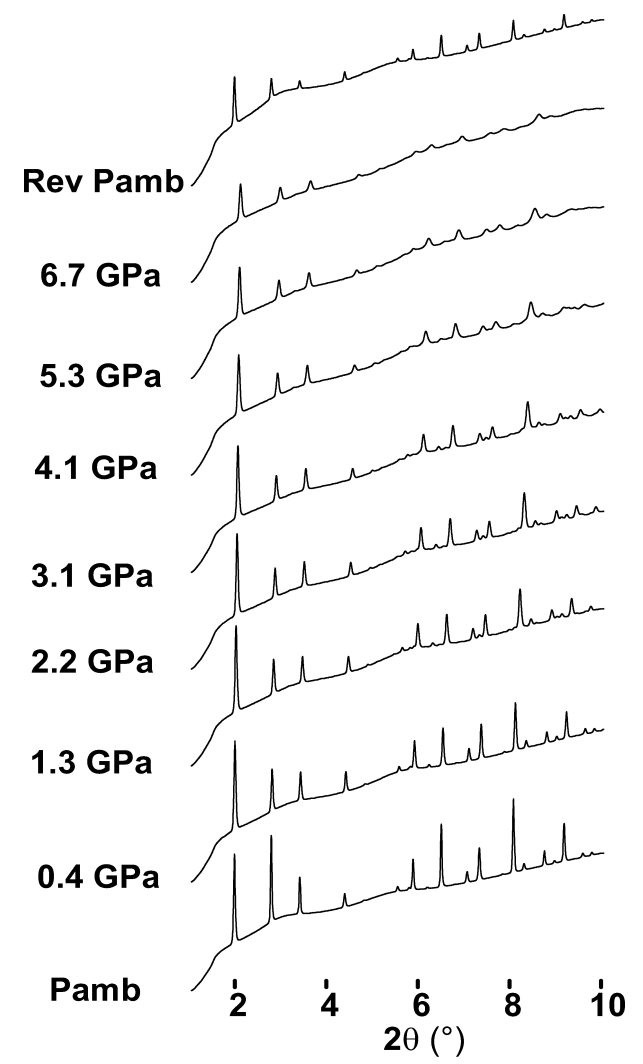

FIGURE 2. Selected integrated powder patterns of hydrated zeolite $\mathrm{Na}-\mathrm{A}$ as a function of pressure. The powder pattern at the top of the figure was collected during decompression.

TABLE 3. Mean axial compressibility of the yugawaralite unit-cell parameters calculated in different pressure ranges

\begin{tabular}{llll}
\hline \hline Mean axial & \multicolumn{3}{c}{ Pressure ranges } \\
\cline { 2 - 4 } compressibility & $10^{-4}-1.5(\mathrm{GPa})$ & $2.0-4.3(\mathrm{GPa})$ & $5.3-10(\mathrm{GPa})$ \\
\hline$\beta_{\mathrm{a}}$ & $1.05(8) 10^{-2}$ & $7.4(6) 10^{-3}$ & $5.29(1) 10^{-3}$ \\
$\beta_{\mathrm{b}}$ & $3.75(3) 10^{-3}$ & $2.1(4) 10^{-3}$ & $2.7(1) 10^{-3}$ \\
$\beta_{\mathrm{c}}$ & $1.07(7) 10^{-2}$ & $9.1(6) 10^{-3}$ & $3.4(1) 10^{-3}$ \\
$\beta_{\beta}$ & $1.92(1) 10^{-3}$ & $1.1(2) 10^{-3}$ & $9(1) 10^{-4}$ \\
\hline
\end{tabular}

the pressure-induced deformations are reversible.

As reported above, the contraction of the $a$ and $c$ parameters is three times greater than that of $b$. The interpretation of this different compressibility can be based on the geometry and position of the extra-framework cation polyhedron. At room pressure the $\mathrm{Ca}$ atom is located on one side of the channels (Figs. 5a and 5b) and is asymmetrically bonded to four framework $\mathrm{O}$ atoms and to four water molecules (Kvick et al. 1986). In reality, the coordination of $\mathrm{Ca}$ is complicated by the presence of two water molecules located at two partially and alternatively occupied positions (not shown in Fig. 5). It is evident from the two projections along $\mathbf{a}$ and $\mathbf{c}$ that the compression of the framework along $\mathbf{b}$ is hindered by the presence of $\mathrm{Ca}-\mathrm{O}_{\text {frame }}$ bonds, which are mainly oriented in this direction. These bonds, pointing toward opposite channel walls, brace the channel apertures, whereas the mobile water molecules allow a greater compressibility along $\mathbf{a}$ and $\mathbf{c}$. To assess this proposed mecha- 

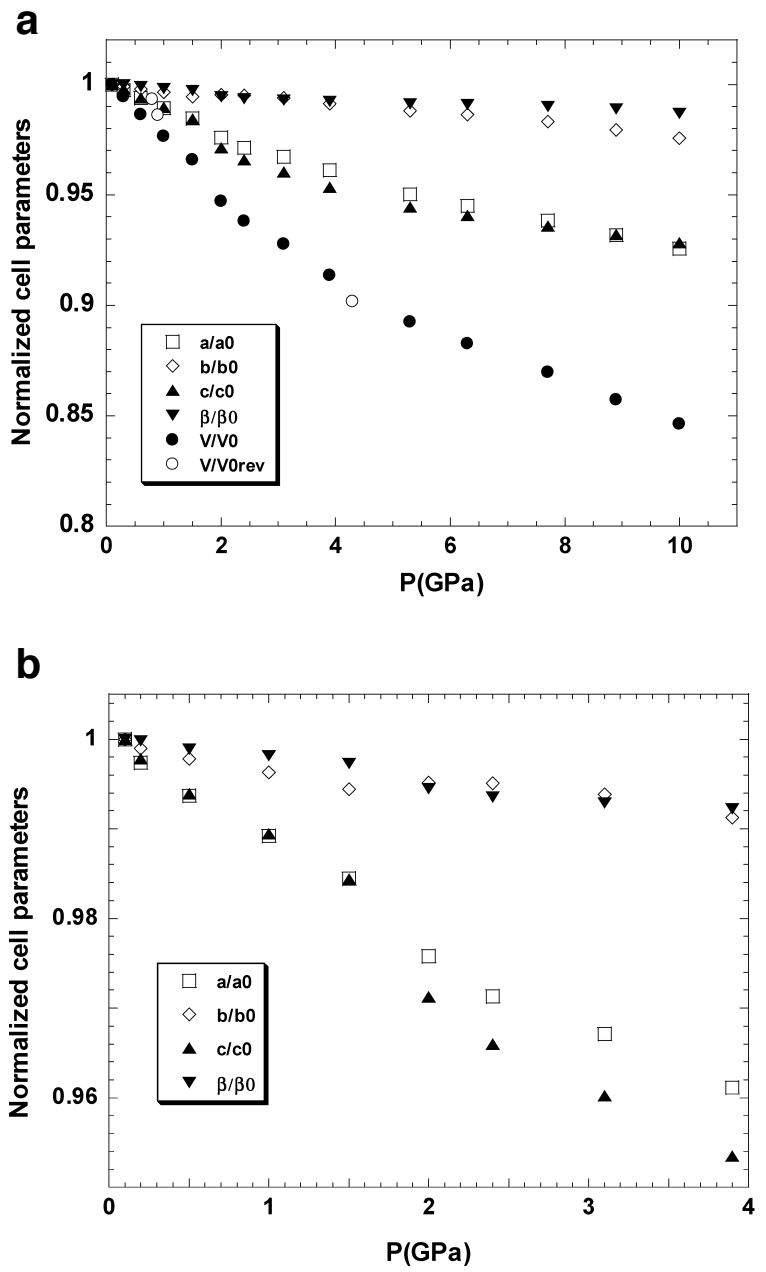

FIGURE 3. Experimental unit-cell parameters of yugawaralite, normalized to room condition values vs. pressure. The data reported in (a) are relative to the complete investigated pressure range and those reported in (b) to the partial range $10^{-4}$ to $4 \mathrm{GPa}$. The errors associated with the cell parameters are smaller than the symbols used.

nism, molecular dynamics computations, based on the experimentally determined cell parameters of YUGA under pressure, are in progress.

\section{Zeolite Na-A}

The structure of the synthetic hydrated zeolite Na-A $\left(\mathrm{Na}_{12} \mathrm{Al}_{12} \mathrm{Si}_{12} \mathrm{O}_{48} \cdot 27 \mathrm{H}_{2} \mathrm{O}, Z=8, F m \overline{3} c\right.$; Gramlich and Meier 1971) can be described in terms of cuboctahedral cages $(\beta$ cages) that are connected by double four-membered rings to form larger $\alpha$ cages. The silica and alumina tetrahedra alternate in an ordered arrangement. The cation sites, refined by Pluth and Smith (1980) from dehydrated Na-A, are: Na1, near the center of six-rings; $\mathrm{Na} 2$ in the plane of the eight-membered rings; and $\mathrm{Na} 3$ in the large cavity opposite a four-membered ring.

The compressibility of ZEOA was first studied by Hazen (1983) and Hazen and Finger (1984) up to 4 GPa by singlecrystal X-ray diffraction, using different penetrating and nonpenetrating pressure-transmitting media. They found that the compressibility was significantly higher when non-penetrat-

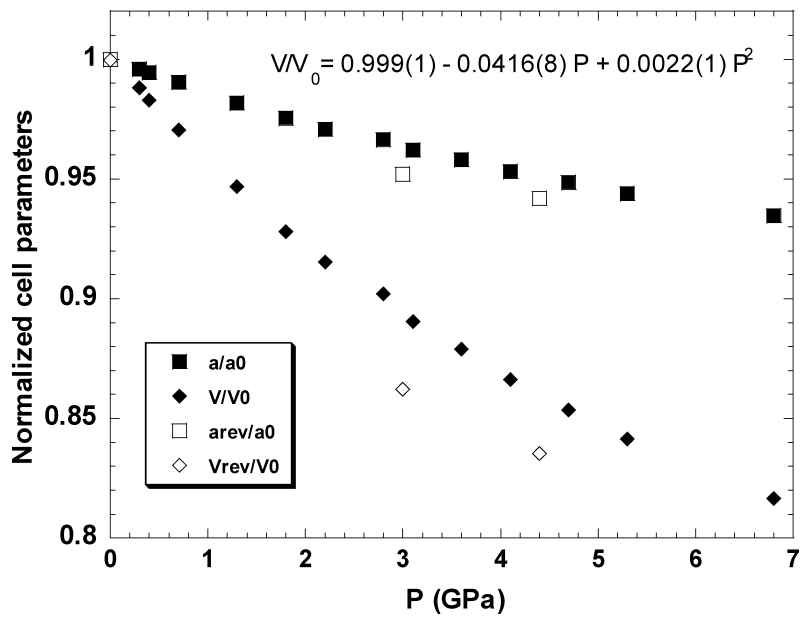

FIGURE 4. Experimental unit-cell parameters of hydrated zeolite $\mathrm{Na}$-A normalized to room condition values vs. pressure. The errors associated with the cell parameters are smaller than the symbols used. The regression line equation is reported at the top of the figure.
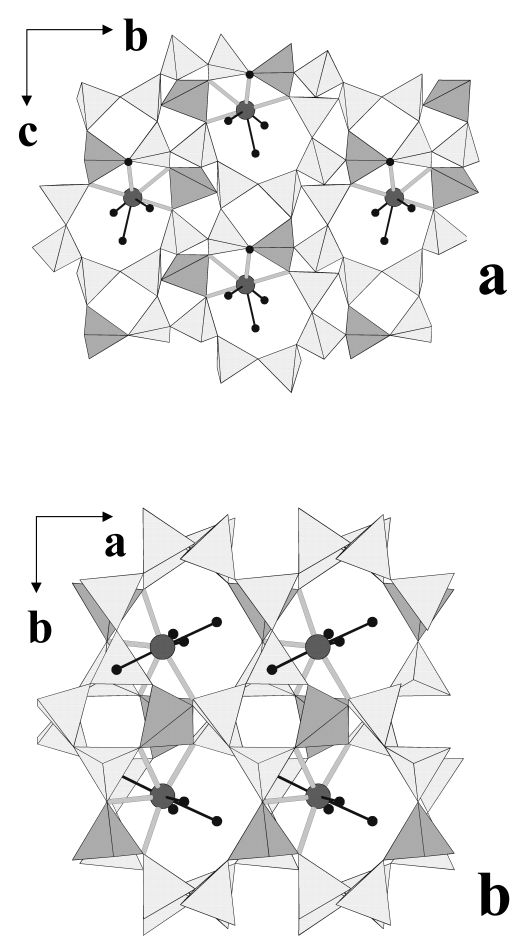

FIGURE 5. Yugawaralite structure at room pressure projected along [100] (a) and [001] (b) directions.

ing pressure-transmitting media were used. The bulk modulus obtained on data up to $2 \mathrm{GPa}$ using glycerol and FC-75 was 21 GPa. More recent work on ZEOA, in different exchanged forms, has mainly focused on pressure-induced amorphization and its reversibility (Huang 1998; Secco and Huang 1999; Huang and Havenga 2001; Rutter et al. 2001). Particular attention was devoted to the study of pressure effects on ionic conduction in these phases (Rutter et al. 2000), since an anomalous increase 
in ionic conductivity was observed up to $1.8 \mathrm{GPa}$, as a result of the increased structural disorder. Upon decompression, conductivity maintained a value higher than that at room pressure.

We now discuss new high-pressure data for hydrated ZEOA collected in the pressure range $10^{-4}$ to $6.8 \mathrm{GPa}$ by means of in situ synchrotron XRPD. The powder patterns shown in Figure 2 indicate that no X-ray amorphization occurs up to about 7 GPa. However, a residual peak broadening and a low peak-tobackground ratio characterize the patterns collected after decompression. This partial reversibility is in agreement with the data of Secco and Huang (1999) and Rutter et al. (2000) and could be the origin of the enhanced ionic conductivity retained by the material after decompression.

Table 2 and Figure 4 show the variation of cell parameters as a function of pressure. In the investigated pressure range, the reductions of $a$ and $V$ parameters $(6.5$ and $18.4 \%$, respectively) are not linear. The linear regression line equation for the normalized $P-V$ dependence is shown in Figure 4. The volume compression data, the isothermal bulk modulus $K_{0}$, and its pressure derivative $K_{0}^{\prime}$ were fitted up to $6.8 \mathrm{GPa}$ with a thirdorder Birch-Murnaghan equation of state. The refined values are $V_{0}=14899(20) \AA^{3}, K_{0}=19.6(6) \mathrm{GPa}$, and $K_{0}^{\prime}=5.1(3)$. If the data are fitted to a second-order equation, $K_{0}$ becomes 22.1(3) $\mathrm{GPa}$. Both bulk modulus values are in close agreement with the $K_{0}=21 \mathrm{GPa}$ obtained by Hazen and Finger (1984).

The same authors, in their study of ZEOA using single crystals and different non-penetrating pressure-transmitting media, reported a volume discontinuity at about $1 \mathrm{GPa}$. Limiting our data to the pressure range $10^{-4}$ to $2 \mathrm{GPa}$ and using a linear fit, we also observed a very slightly decreasing slope for the volume $P$-dependence at a similar pressure value.

The data extracted from three XRPD patterns collected during the decompression of the sample are reported in Table 2 and Figure 4. The values corresponding to room pressure indicate that the original unit-cell parameters are completely recovered after decompression; however the reverse path shows a hysteresis effect with respect to the forward one.

\section{COMPARATIVE DISCUSSION}

Below we compare the high-pressure behavior of the zeolites studied in this paper with that of other natural zeolites studied under similar experimental conditions (heulandite: HEUL, Vezzalini et al. 2001; scolecite: SCOL, Ballone et al. 2002; bikitaite: BIKI, Ferro et al. 2002) and, in general, with the available literature data obtained with non-penetrating $P$ transmitting media. The deformation mechanisms induced by $\mathrm{H} P$ and $\mathrm{H} T$ in these porous materials are also compared.

\section{Compressibility}

In Figure 6 we compare the pressure dependence of the lattice volumes of YUGA and ZEOA with that of the other zeo-

FigURE 6. Unit-cell volumes, normalized to room condition values, vs. pressure for YUGA and ZEOA (this work), heulandite (Vezzalini et al. 2001), scolecite (Ballone et al. 2002), and bikitaite (Ferro et al. 2002). The bulk modulus was calculated up to $6.8,3.5,4.0,5.7$, and $5.0 \mathrm{GPa}$ for ZEOA, heulandite, YUGA, bikitaite, and scolecite, respectively.
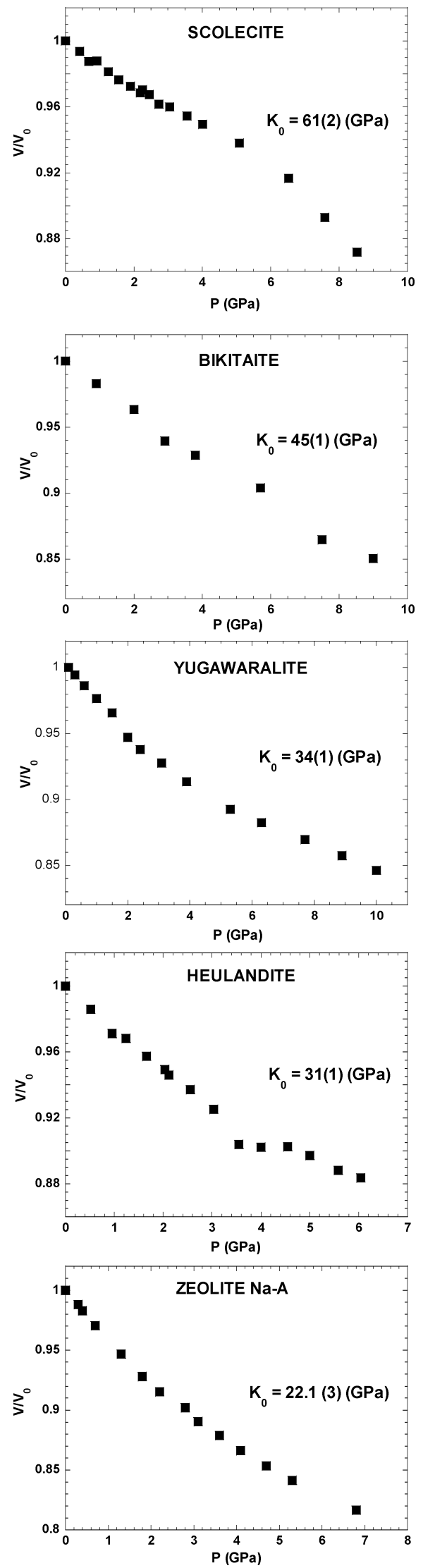
lites studied under the same experimental conditions. We can single out three different trends in compressibility: with increasing pressure HEUL, YUGA, and ZEOA show a compressibility decrease, and SCOL an increase, while the compressibility of BIKI does not vary with pressure. The unusual behavior of SCOL, rarely occurring in silicate minerals, was, however, also observed for gillespite-type phases (Miletich 2000) and was interpreted by Ballone et al. (2002), on the basis of ab initio molecular dynamics calculations, as due to a phase transition involving structural modifications in the extra-framework water system.

All the bulk modulus values available for zeolites compressed with non-penetrating media are plotted in Figure 7 against the so called framework density (FD) (Baerlocher et al. 2001), i.e., the number of tetrahedrally coordinated atoms per $1000 \AA^{3}$. These $K_{0}$ cover a large variability range from the minimum for ZEOA (22.1 GPa) to the maximum for SCOL (61 GPa); however, in general, zeolites turn out to be easily collapsible under pressure, as expected for this type of very open structures. The triangles represent the samples studied by synchrotron XRPD, while the squares are $K_{0}$ values reported in the literature for zeolites studied by single-crystal X-ray diffraction. The close agreement between the results of the two techniques should be noted.

From Figure 7 no clear correlation can be singled out between FD and $K_{0}$ for all the topologies. This could be ascribed to the fact that the compressibility of these complex structures is certainly strongly influenced not only by the framework density, but also by the type, amount, and location of the extraframework cations and water molecules.

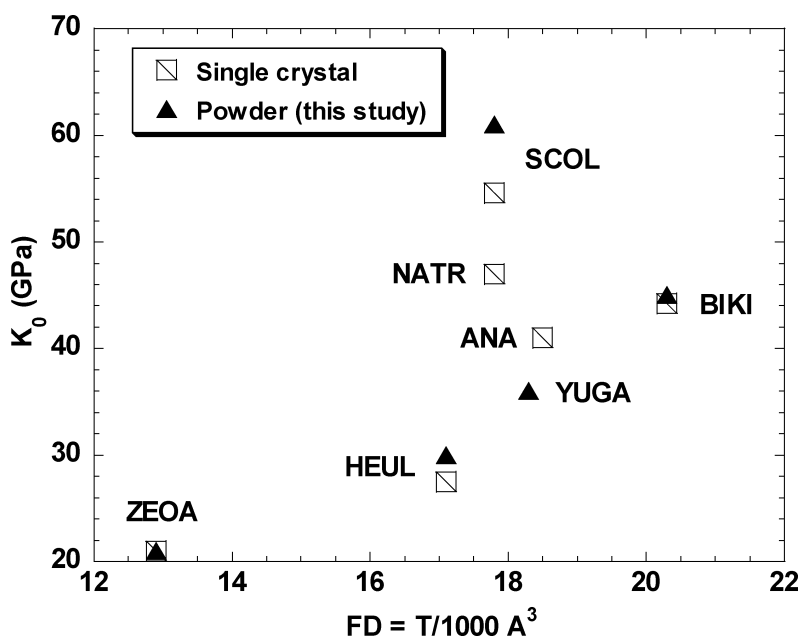

FigURE 7. Bulk modulus $\left(K_{0}\right)$ of selected zeolites as a function of framework density (FD). Triangles: samples studied by synchrotron radiation $\mathrm{X}$-ray powder diffraction; squares: samples studied by single crystal X-ray diffraction (ZEOA, Hazen and Finger 1984; heulandite HEUL, Comodi et al. 2001; analcime ANA, Hazen and Finger 1979; natrolite NATR, Kholdeev et al. 1987; SCOL, Comodi et al. 2002; bikitaite BIKI, Comodi et al. 2003).

\section{Comparison between the deformation mechanisms induced by high pressure or high temperature}

As the high-temperature behavior of the zeolites discussed in this work is known in details, we can compare the deformation mechanisms of these different frameworks under high-pressure and high-temperature conditions. Contrary to the behavior observed under compression, dehydration processes in zeolites involve water loss and extra-framework cation rearrangements, and therefore we will focus our attention on the framework distortions.

The flexibility of zeolites was rationalized on the basis of the Rigid Unit Mode model (Dove et al. 1995; Hammonds et al. 1997, 1998), which described the zeolites as frameworks of corner-linked rigid tetrahedra, able to distort by modifying their internal T-O-T angles. Following Baur (1992a,b, 1995), zeolite frameworks can be defined as "flexible" or "inflexible" upon changes of the physico-chemical conditions. The flexible structures are classified as collapsible or non-collapsible; in collapsible frameworks the T-O-T hinges co-rotate, while in the noncollapsible ones the hinges anti-rotate, preventing cell volume changes.

On the basis of the observed cell parameter variations, YUGA is collapsible to quite a similar extent under both HT (Alberti et al. 1996) and HP. In particular, the cell volume contraction of YUGA at $\mathrm{HP}(15 \%)$ is slightly higher than that at HT (12\%). Moreover, the extent of contraction of each unitcell parameter under the two conditions is significantly different, suggesting different deformation mechanisms.

In contrast, ZEOA is not collapsible at high temperature (Pluth and Smith 1980), but is highly compressible under high pressure. A similar behavior was also observed for bikitaite (Ferro et al. 2002; Quartieri et al. 2002). The anomalously low collapsibility of ZEOA and bikitaite under high temperature was interpreted on the basis of the model proposed by Baur (1992a,b), i.e., anti-rotation of the T-O-T angles. Concerning bikitaite, the analysis of the computational results for its deformation mechanism at high pressure revealed that, contrary to that observed at high temperature, all T-O-T angles co-rotate and decrease as a function of pressure. As a consequence the volume decrease under these conditions is about one order of magnitude higher than that observed at high temperature.

\section{ACKNOWLEDGMENTS}

This paper is dedicated to Orazio Ferro, who died prematurely at age 33 years. He was deeply involved in this research and made a large contribution to the present paper.

The European Synchrotron Radiation Facility is kindly acknowledged for allocation of beam-time under proposal nos. $\mathrm{CH}-831$ and $\mathrm{CH}-1019$. This work was supported by the Italian MIUR (COFIN2001 "Zeolites, materials of interest for industry and environment: synthesis, crystal structure, stability, and applications") and CNR. The authors warmly thank M. Hanfland for his careful advice during high-pressure experiments and M. Welch and two anonymous referees for their useful suggestions, which improved the manuscript.

\section{REFERENCES CITED}

Alberti, A., Quartieri, S., and Vezzalini, G. (1996) Thermal behaviour of zeolites: single crystal X-ray study of dehydration and rehydration mechanism in yugawaralite. European Journal of Mineralogy, 8, 1273-1282.

Alivisatos, A.P. (1996) Semiconductor clusters, nanocrystals, and quantum dots. Science, 271, 933-937.

Angel, R.J. (2001) Equations of state. In R.M. Hazen and R.T. Downs Eds., Highpressure, high-temperature crystal chemistry. Reviews in Mineralogy and Geochemistry, 41, 35-59.

Baerlocher, Ch., Meier, W.M., and Olson, D.H. (2001) Atlas of zeolite framework 
types. Elsevier, The Netherlands.

Ballone, P., Quartieri, S., Sani, A., and Vezzalini, G. (2002) High-pressure deformation mechanism in scolecite: a combined computational-experimental study. American Mineralogist, 87, 1194-1206.

Baur, W.H. (1992a) Why the open framework of zeolite A does not collapse, while the dense framework of natrolite is collapsible. Proceedings of Polish-German Zeolite Colloquium. M. Rozwadowski, Ed., Nicholas Copernicus University Press., Torun, 11-19.

(1992b) Self-limiting distorsion by antirotating hinges of flexible but noncollapsible frameworks. Journal of Solid State Chemistry, 97, 243-247.

- (1995) Framework mechanics: limits to the collapse of tetrahedral framework. In M. Rozwadowski, Ed., Proceedings $2^{\text {nd }}$ Polish-German Zeolite Colloquium, 171-185. Nicholas Copernicus University Press, Torun.

Bazhan, I.S., Kholdeev, O.V., and Fursenko, B.A. (1999) Phase transformations in scolecite at high hydrostatic pressure. Doklady Akademy Nauk, 364, 97-100.

Belitsky, I.A., Gabuda, S.P., and Moroz, N.K. (1987) Increasing in molecular diffusion rate in zeolite at high hydrostatic pressures. Doklady Academy Nauk, 292, 1191-1195.

Belitsky, I.A., Fursenko, B.A., Gabuda, S.P., Kholdeev, O.V., and Seryotkin, Yu.V. (1992) Structural transformations in natrolite and edingtonite. Physics and Chemistry of Minerals, 18, 497-505.

Birch, F. (1952) Elasticity and constitution of the Earth's interior. Journal of Geophysical Research, 57, 227-286.

Bish, D.L. and Carey, J.W. (2001) Thermal behavior of natural zeolites. In D.L. Bish and D.W. Ming, Eds., Reviews in Mineralogy and Geochemistry, 45, 403452. The Mineralogical Society of America and The Geochemical Society, Washington, D.C.

Comodi, P., Gatta, G.D., and Zanazzi, P.F. (2001) High-pressure structural behavior of heulandite. European Journal of Mineralogy, 13, 497-505.

- (2002) High-pressure structural behaviour of scolecite. European Journal of Mineralogy, 14, 567-574.

(2003) Effects of pressure on the structure of bikitaite. European Journal of Mineralogy, 15, 267-295.

Dove, M.T., Heine, V., and Hammonds, K.D. (1995) Rigid Unit Modes in framework silicates. Mineralogical Magazine, 59, 629-639.

Fei, Y. and Wang, Y. (2000) High-pressure and high-temperature powder diffraction. In R.M. Hazen and R.T. Downs, Eds., High-pressure, high-temperature crystal chemistry. Reviews in Mineralogy and Geochemistry, 41, 521-557. The Mineralogical Society of America and the Geochemical Society, Washington, D.C.

Ferro, O., Quartieri, S.,Vezzalini, G., Fois, E., Gamba, A., and Tabacchi, G. (2002) High-pressure behaviour of bikitaite: an integrated theoretical and experimental approach. American Mineralogist, 87, 1415-1425.

Finger, L.W., Cox, D.E., and Jephcoat, A.P. (1994) A correction for powder diffraction peak asymmetry due to axial divergence, Journal of Applied Crystallography, 27, 892-900.

Forman, R.A., Piermarini, G.J., Barnett, J.D., and Block, S. (1972) Pressure measurements made by utilization of the ruby sharp-line luminescence. Science, $176,284-286$.

Gillet, P., Malézieux, J.M., and Itiè, J.P. (1996) Phase changes and amorphization of zeolites at high pressures: the case of scolecite and mesolite. American Mineralogist, 81, 651-657.

Goryainov, S.V. and Smirnov, M.B. (2001) Raman spectra and lattice-dynamical calculations of natrolite. European Journal of Mineralogy, 13, 507-519.

Goryainov, S.V., Fursenko, B.A., and Belitsky, I.A. (1996) Phase transitions in analcime and wairakite at low-high temperatures and high pressure. Physics and Chemistry of Minerals, 23, 297-298.

- (1999) Raman spectroscopy of phase transition and amorphyzation of wairakite at high pressure. Doklady Akademy Nauk, 369, 70-73.

Gramlich, W. and Meier, W.M. (1971) The crystal structure of hydrated NaA: a detailed refinement of a pseudosymmetric zeolite structure. Zeitschrift für Kristallographie, 133, 134-149.

Hammersley, A.P., Svensson, S.O., Hanfland, M., Fitch, A.N., and Häusermann, D. (1996) Two-dimensional detector software: from real detector to idealised image or two-theta scan. High Pressure Research, 14, 235-248.

Hammonds, K.D., Deng, H., Heine, V., and Dove, M.T. (1997) How floppy modes give rise to adsorption sites in zeolites. Physical Review Letters, 78, 37013704.

Hammonds, K.D., Heine, V., and Dove, M.T. (1998) Rigid-Unit modes and the quantitative determination of the flexibility possessed by zeolite frameworks. Journal of Physical Chemistry, B102, 1759-1767.

Hazen, R.M. (1983) Zeolite molecular sieve 4A: anomalous compressibility and volume discontinuity at high pressure. Science, 219, 1065-1067.

Hazen, R.M. and Finger, L.W. (1979) Polyhedral tilting: a common type of pure displacive phase transition and its relationship to analcite at high pressure. Phase
Transitions, 1, 1-22.

(1984) Compressibility of zeolite 4A is dependent on the molecular size of the hydrostatic pressure medium. Journal of Applied Physics, 56, 1838-1840.

Huang, Y. (1998) IR spectroscopic study of the effect of high pressure on zeolites Y, A and sodalite. Journal of Material Chemistry, 8, 1067-1071.

Huang, Y. and Havenga, E.A. (2001) Why do zeolites with LTA structure undergo reversible amorphization under pressure? Chemical Physics Letters, 345, 6571.

Kholdeev, O.V., Belitsky, I.A., Fursenko, B.A., and Goryainov, S.V. (1987) Structural phase transformation in natrolite at high pressures. Doklady Akademii Nauk, 297, 946-950.

Kvick, ̊.,, Artioli, G., and Smith, J.V. (1986) Neutron diffraction study of the zeolite yugawaralite at $13 \mathrm{~K}$. Zeitschrift für Kristallographie, 174, 265-281.

Larson, A.C. and Von Dreele, R.B. (1994) GSAS-General Structure Analysis System. Report LAUR 86-748, Los Alamos National Laboratory, Los Alamos, New Mexico.

Le Bihan, T., Heathman, S., Darracq, S., Abraham, C., Winand, J-M., and Benedict, U. (1996) High pressure X-ray diffraction studies of UX3 (X = Al, Si, Ga, Ge, In, Sn). High Temperatures-High Pressures, 27/28, 157-162.

Lee, Y., Hriljac, J.A., Vogt, T., Parise, J.B., Edmondson, M.J., Anderson, P.A., Corbin, D.R., and Takaya, N. (2001) Phase transition of zeolite RHO at high-pressure. Journal of the American Chemical Society, 123, 8418-8419.

Lee, Y., Vogt, T., Hriljac, J.A., Parise, J.B., and Artioli, G. (2002) Pressure-induced volume expansion of zeolites in the natrolite family. Journal of American Chemical Society, 124, 5466-5475.

Liu, H., Secco, R.A., and Huang, Y. (2001) Pressure-induced amorphization of hydrated Na-X zeolite. Physical Chemistry Communications, 8, 1-3.

Mao, H.K., Xu, J., and Bell, P.M. (1986) Calibration of the ruby pressure gauge to $800 \mathrm{Kbar}$ under quasi-hydrostatic conditions. Journal of Geophysical Research, 91, 4673-4676.

Miletich, R. (2000) The tetragonal-to-tetragonal phase transition in gillespite-type phases. Is there elastic softening at high pressures? VIII EMPG, Bergamo (Italy) $16-19 / 4 / 2000$, p. 71

Moroz, N.K., Kholopov, E.V., Belitsky, I.A., and Fursenko, B.A. (2001) Pressureenhanced molecular self-diffusion in microporous solids. Microporous and Mesoporous Materials, 42, 113-119.

Pluth, J.J. and Smith, J.V. (1980) Accurate redetermination of crystal structure of dehydrated zeolite A. Absence of near zero coordination of sodium. Refinement of Si,Al-ordered superstructure. Journal of American Chemical Society, $102,4704-4708$.

Quartieri, S., Vezzalini, G., Ferro, O., Fois, E., Ceriani, C., Tabacchi, G., and Gamba, A. (2002) High-pressure and high-temperature behaviour of the zeolite bikitaite: an integrated theoretical and experimental approach. Proceedings of the $18^{\text {th }}$ General Meeting of the International Mineralogical Association, 1-6 September 2002, Edinburgh, Scotland, p. 89.

Rutter, M.D., Secco, R.A., and Huang, Y. (2000) Ionic conduction in hydrated zeolite Li-, Na- and K-A at high pressures. Chemical Physics Letters, 331, 189195.

Rutter, M.D., Uchida, T., Secco, R.A., Huang, Y., and Wang, Y. (2001) Investigation of pressure-induced amorphization in hydrated zeolite $\mathrm{Li}-\mathrm{A}$ and $\mathrm{Na}-\mathrm{A}$ using synchrotron X-ray diffraction. Journal of Physics and Chemistry of Solids, 62, 599-606.

Secco, R.A. and Huang, Y. (1999) Pressure-induced disorder in hydrated Na-A zeolite. Journal of Physics and Chemistry of Solids, 60, 999-1002.

Thomson, P., Cox, D.E., and Hastings, J.B. (1987) Rietveld refinement of DebyeScherrer synchrotron X-ray data from $\mathrm{Al}_{2} \mathrm{O}_{3}$. Journal of Applied Crystallography, 20, 79-83.

Velde, B. and Besson, J.M. (1981) Raman spectra of analcime under pressure. Physics and Chemistry of Minerals, 7, 96-99.

Vezzalini, G., Quartieri, S., Sani, A., and Levy, D. (2001) The structural modifications induced by high pressure in scolecite and heulandite: in-situ synchrotron X-ray powder diffraction study. In A. Galarneau, F. Di Renzo, F. Fajula, and J. Vedrine, Eds., Studies in surface sciences and catalysis, 135. Elsevier Science B.V., Amsterdam.

Weidner, D.J., Huang, Y., Chen, G., Hando, J., and Vaughan, M.T. (1998) Rheology measurements at high pressure and temperature. In M.H. Manghnani and T. Yagy, Eds., Properties of Earth and Planetary Materials at High Pressure and Temperature, 473-480. American Geophysics Union, Washington, D.C.

Yamanaka, T., Nagay, T., and Tsuchiya, T. (1997) Mechanism of pressure-induced amorphization. Zeitschrift für Kristallographie, 212, 401-410.

MANUSCRIPT RECEIVED NOVEMBER 9, 2002

MANUSCRIPT ACCEPTED MARCH 25, 2003

MANUSCRIPT HANDLED BY MARK WELCH 